\title{
Comentários acerca do trabalho feminino e da luta de classes em Parque Industrial de Patrícia Galvão
}

\author{
Sileyr dos Santos Ribeiro \\ Universidade Federal do Espírito Santo \\ Vitória, Brasil \\ Recebido em: 30/04/2019 \\ Aceito em: 11/o6/2019
}

Resumo: O romance Parque Industrial (1994), de Patrícia Galvão, foi publicado em 1933 sob o pseudônimo de Mara Lobo. A obra denuncia o assédio moral e sexual a que as operárias foram submetidas durante o processo de industrialização brasileiro. Dialogando com o conceito de regime estético da arte, de Jacques Rancière (2009), articulamos aos comentários do romance algumas considerações de Auguste Bebel (1910) e de Domenico Losurdo (2015), no que tange, respectivamente, à problemática entorno do trabalho das mulheres durante o início do século passado e à visão da luta de classes feminina associada a um contexto macropolítico de dissimetria social. Palavras-chave: Parque Industrial. Luta de classes. Luta de classes feminina. Operárias.

Abstract: The novel Parque Industrial (1994) of Patrícia Galvão was
published in 1933 under the pseudonym of Mara Lobo. The book denounces
the moral and sexual harassment to which workers were subjected during
the process of Brazilian industrialization. In dialogue with the concept of the
aesthetic regime of art, by Jacques Rancière (2009), we articulate to the
comments of the novel some considerations of Auguste Bebel (1910) and
Domenico Losurdo (2015), concerning, respectively, the problematic
surroundings of the work of the women in the early part of the last century
and the vision of the female class struggle associated with a macropolitical
context of social dissimetry. Keyword: Parque Industrial. Class struggle. Female class struggle. Working women.

Resumen: La novela Parque Industrial (1994), de Patricia Galvão, fue publicada en 1933 bajo el pseudónimo de Mara Lobo. La obra denuncia el acoso moral y sexual a que las obreras fueron sometidas durante el proceso de industrialización brasileño. Dialogamos con el concepto de régimen estético del arte, de Jacques Rancière (2009) y articulamos a los comentarios de la novela algunas consideraciones de Auguste Bebel (1910) y de Domenico Losurdo (2015), en lo que se refiere, respectivamente, a la problemática circundante del trabajo de las mujeres durante el inicio del siglo pasado ya la visión de la lucha de clases femenina asociada a un contexto macropolítico de disimetría social.

Palabras clave: Parque Industrial. Lucha de clases. Lucha de clases femenina. Trabajadores. 


\section{Introdução}

No conto "Rumpelstiltzchen", dos Irmãos Grimm (2012), é levada à presença do Rei uma bela donzela que, segundo o pai, saberia transformar fios de palha em ouro. $\mathrm{O}$ monarca coloca sob suspeição a prenda moça e resolve encerrá-la em um quarto com uma roca de fiar, prometendo desposá-la, caso se concretizasse as palavras do moleiro, ou matá-la, caso se desse o oposto. Desesperada, a jovem chora. Aparece um duende que, aceitando os únicos bens dos quais a moça dispunha - um colar e, depois, um anel -, executa por duas vezes a empreitada real. O Rei, avaro, resolve testá-la ainda uma vez. A pobre donzela, sem ter mais posses a ofertar ao Duende, aceita entregar-lhe o primeiro filho como pagamento pelos favores. Após concluir com êxito o teste, a agora Rainha tem seu primeiro filho e o Duende vem saldar o débito. Porém, comovido com as copiosas lágrimas da mãe, o homenzinho propõe à Rainha que, em três dias, adivinhe seu nome ou lhe entregue o filho. Após o Rei retornar de uma caçada, conta que observou na floresta um homenzinho dançando e cantarolando o incógnito nome "Rumpelstiltzchen" - e imediatamente comunica à Rainha. Furioso com a descoberta do nome, o Duende corre para longe.

Decerto, há uma figuração no imaginário social da mulher associada à instância da tecelagem. Na literatura, podemos observar tal prevalência tanto em contos de fadas como em "Rumpelstiltzchen" e em "A Bela Adormecida" (GRIMM, 2012) -, quanto na própria Odisseia. Na epopeia homérica, Penélope, esposa de Ulysses, se dispõe a aceitar o cortejo dos pretendentes à sua mão, porém, estipula como condição para o matrimônio que terminasse de tecer um sudário para o sogro, Laerte. Durante o dia, Penélope borda, porém, ao anoitecer desfaz todo o trabalho, enquanto o marido, desaparecido após a Guerra de Tróia, cose sua própria história e busca não cair em desmemória por meio de suas narrativas. As personagens tecelãs adiam, por meio de suas atividades laborais e cada qual à sua maneira, o encontro com o indesejável: em "Rumpelstiltskin", com a morte; na Odisseia, com um novo enlace. Enquanto no conto dos Irmãos Grimm a donzela teria que fiar para não morrer, a personagem Sherazade, nas Mil e uma Noites, deveria narrar para não morrer.

De modo similar, são tão inúmeras quanto antigas as metáforas que relacionam a arte de contar à tecelagem, sugerindo uma ligação entre o trabalho intelectual e o trabalho manual, no que tange, principalmente, às estórias populares. Percebendo o declínio da arte de narrar, Walter Benjamin (1994) associa ao surgimento da técnica uma 
nova forma de pobreza, caracterizada pela falência das narrativas embasadas em experiências genuínas. Na sociedade manufatureira, os artesãos corporificavam uma experiência profundamente ligada ao labor, de forma que fiavam e narravam estórias tecidas pelo encontro entre a experiência sedentária e aquelas trazidas de terras longínquas pelos viajantes e mercadores.

Em seu livro Partilha do sensível (2009), Jacques Rancière reconhece entre o final do século XVIII e o início do século XIX um período de ruptura e de grande transformação no fazer artístico. O pensador franco-argelino analisa os regimes das artes relacionando cada qual a uma partilha político-social historicamente constituída. Assim, se o regime ético das artes condenava como falsas as imagens de acordo com a suspeição de seu ser e o regime poético estabelecia a forma de se representar de acordo com a baixeza ou a elevação do tema e do público ao qual se destinava - tragédia para os nobres, comédia para a plebe -, o regime estético da arte, indissociável da democracia, desfaz a correlação entre tema e modo de representação e se instaura na passagem dos acontecimentos e dos personagens grandiosos à vida dos anônimos, à glória do "qualquer (tema) antes da técnica." (RANCIÈRE, 2009, p. 48). Assim, o regime estético indiscerne logos e pathos e rompe com o modelo mimético platônico, o qual relaciona a arte a uma verdade.

Se no século XVIII, em consonância com a herança aristotélica, os saberes eram dispostos em gêneros e subgêneros de acordo com três categorias beletristas utilizadas na composição da obra - a inventio, que determinava o assunto de que se trataria; a dispositivo, que prescrevia a disposição dos trechos de um discurso; e a elocutio, que determinava o tom a ser adotado nas obras de acordo com a dignidade do tema -, no século XIX, a literatura se "torna propriamente a atividade daquele que escreve" (RANCIÈRE, 1995, p. 26). Opera-se, portanto, uma revolução estética, cuja equalização de temas, personagens e referentes repercute no modo de se perceber a sociedade e a partilha do sensível.

É preciso sair do esquema preguiçoso e absurdo que opõe o culto estético da arte pela arte à potência ascendente do trabalho operário. É como trabalho que a arte pode adquirir o caráter de atividade exclusiva. [...] Arte e produção poderão se identificar no tempo da Revolução Russa, porque dependem de um mesmo princípio de repartição do sensível, de uma mesma virtude do ato que inaugura uma visibilidade ao mesmo tempo em que fabrica objetos (RANCIÈRE, 2009, p. 68 apud SOARES, 2017, p. 123). 
Deste modo, tendo em vista que a construção do texto literário no regime estético das artes é profundamente ligada à partilha política e socialmente constituída, perguntamo-nos: a) como a literatura captaria a potência da luta de classes e a acentuada desigualdade política e social na partilha dos bens de consumo e como poderia contribuir no retrato crítico do Brasil, profundamente marcado pelo saqueio colonial e pela condição de nação colonizada? b) Como uma obra literária, enquanto trabalho ao mesmo tempo estético e político, corporifica a resistência, critica a divisão do trabalho e concorre na redistribuição da partilha do sensível, na medida em que equaliza temas, modos e formas, e destitui as hierarquias? Segundo Luís Eustáquio Soares (2017), algumas obras brasileiras, como Parque Industrial (1994),

destituem a partilha desigual imperialista, ao visibilizar o trabalho dos colonizados, no sensível estético da página, por sua emancipação política ao mesmo tempo inteligível e sensível, no mesmo ato que torna indiscernível a reconfiguração democrática da partilha do sensível na arte e na história (SOARES, 2017, p.124).

A obra Parque Industrial (1994), de Patrícia Galvão - Pagu -, publicada sob o pseudônimo de Mara Lobo quatro anos após o crash de 1929, denuncia o assédio moral e sexual a que as operárias pobres foram submetidas durante $\mathrm{o}$ processo de industrialização brasileiro no século passado. A obra apresenta personagens tipos que, alegorizando segmentos economicamente oprimidos, demonstram os dispositivos biopolíticos que cerceiam a classe trabalhadora de São Paulo. Embora Parque Industrial tenha como protagonistas tanto a propriedade privada quanto os meios de produção, "razão pela qual a narrativa se concentre na pintura de quadros que fixam, como um mosaico fotográfico documental, a opressão de classe na periferia da civilização burguesa" (SOARES, 2017, p. 133), a obra encerra uma importante crítica às desigualdades de gênero e ao subjugamento das mulheres em um contexto patriarcal.

Domenico Losurdo (2015) analisa a subalternidade de gênero dentro de um macrocosmo da luta de classes e crê que a sociedade capitalista comporta em seu seio um modelo familiar patriarcal e assimétrico, no qual tanto a mulher quanto os filhos são subjugados pelo homem. Não obstante tal configuração se trate de um microcosmo que emula uma ordem global, marcada pela violência econômica e por uma acentuada dissimetria social, será sobre as mulheres que veremos uma forma singularmente humilhante de exercício do poder. Consoante Losurdo (2015), o núcleo familiar moderno teria como fundamento uma relação de escravidão na qual, de forma aparente ou 
disfarçada, homem e mulher incorporam respectivamente os papéis de burguês e de proletário.

Segundo Losurdo (2015), o Manifesto Comunista (1998) conclama à libertação não apenas as classes exploradas - com a célebre frase "Proletários de todos os países, univos! -", mas também as nações oprimidas - a Polônia, pela Rússia e a Irlanda, pela GrãBretanha. Assim, Marx e Engels (1998) criticam vigorosamente a subalternização do proletariado e declaram a necessidade de se julgar a divisão do trabalho sob um ponto de vista não apenas nacional, mas também internacional e, igualmente, de se possibilitar uma política externa de apoio às nações oprimidas. As dissimetrias socioeconômicas dos países privados de sua soberania nacional incorporam em sua lógica uma divisão do trabalho e de privação de sua independência ainda mais ignominiosa, "sobretudo aos povos sujeitados ao domínio e saqueio colonial". (LOSURDO, 2015, p. 28).

Ao longo da história, a luta de classes adquiriu uma multiplicidade derivada de diferentes desníveis, quer de uma nação em relação a outra no cenário internacional, quer por uma diferença de classes em um mesmo país, quer pela subalternidade da mulher em relação ao homem. Nestes aspectos,

\begin{abstract}
A luta de classes que tem como protagonistas os povos em condições coloniais ou semicoloniais ou de origem colonial; a luta travada pela classe operária nas metrópoles capitalista (na qual se concentra a reflexão de Marx e Engels); a luta das mulheres contra a "escravidão doméstica". Cada uma dessas três lutas põe em discussão a divisão do trabalho vigente em âmbito internacional, nacional e familiar. "Relação de coerção" (Zwangsverhältniß) é a que na sociedade burguesa existe entre capital e trabalho, mas pode-se fazer a mesma consideração para as outras duas relações. As três lutas de emancipação põem em discussão as três "relações de coerção" fundamentais que constituem o sistema capitalista (LOSURDO, 2015, p. 64).
\end{abstract}

Consoante Losurdo (2015), a coação do sexo feminino pelo masculino seria a gênese da opressão de classe, pois, remontando à derrubada do matriarcado e à assunção do homem do comando da casa, a subalternização de gênero reduziu a figura feminina à condição de mero instrumento reprodutivo, por vezes, tal papel aparece sob outras roupagens, enfeitado ou abrandado, mas nunca é totalmente abandonado.

August Bebel, em seu Woman and Socialism (1910) aponta já nas primícias do século passado, na incorporação da mão de obra feminina ao mercado de trabalho, a inferioridade de salários pagos às mulheres em comparação aos homens. As justificativas para tal desigualdade residem nas "interrupções" temporárias - como a gravidez - e na suposta desvantagem de força em relação aos homens em um mundo dominado pela 
“lógica do mais forte”. Dentro do raciocínio de obter a máxima exploração com o mínimo de pagamentos pela mão de obra, o capitalismo incorpora à sua lógica a substitutibilidade, na qual "mulheres substituem homens e mulheres, por sua vez, são substituídas por jovens e crianças. Esse é o 'regime moral' da indústria moderna” (BEBEL, 1910, p. 211). Com isso, receber salários inferiores aos dos homens e ter uma menor articulação para reivindicar melhorias são "virtudes" apreciadas pelos empregadores:

Como trabalhadora, a mulher casada é muito mais "atenta e dócil" do que a solteira. A consideração por seus filhos a impele a exercer sua força ao máximo para prover o necessário para seu sustento e ela, portanto, silenciosamente se submeteria a muito mais do que as solteiras se submeteriam, por bem menos do que um operário. De modo geral, as operárias raramente se combinam com os seus colegas para obterem melhores condições de trabalho. Isso também aumenta seu valor aos olhos dos empregadores; às vezes elas ainda são uma boa maneira de subjugar trabalhadores rebeldes. Além disso, mulheres são mais pacientes e possuem maior compreensão e um gosto mais apurado, qualidades que as fazem mais adequadas para muitos tipos de trabalho do que os homens (BEBEL, 1910, p. 210, tradução nossa) ${ }^{1}$.

Assim, com a crescente industrialização, o campo de trabalho feminino aumentou gradativamente a cada ano, porém, sem se aperfeiçoarem as condições da mulher nos setores ocupados. Dos vários fatores que concorreriam direta ou indiretamente na manutenção de tal situação, Bebel (1910) destaca, além da ausência de direitos, a pouca resistência e articulação das mulheres, mais facilmente dobráveis à lógica capitalista do trabalho:

Os esforços dos empregadores para prolongar o dia de trabalho, a fim de extrair maiores lucros de seus trabalhadores, são enfrentados com pouca resistência pelas mulheres trabalhadoras. Isso explica porque na indústria têxtil, por exemplo, em que mais da metade dos trabalhadores são mulheres, o dia de trabalho é o mais longo. Era necessário, portanto, que a proteção do governo, limitando as horas de trabalho, começasse com essa indústria. As mulheres que estão acostumadas a um dia de trabalho sem fim por sua atividade doméstica, submetem-se

\footnotetext{
1"As a worker the married woman is "far more attentive and docile" than the unmarried one. Consideration for her children compels her to exert her strength to the utmost in order to earn what is needful for their livelihood, and she therefore quietly submits to much that the unmarried working woman would not submit to, far less so the working man. As a rule working women rarely combine with their fellow workers to obtain better working conditions. That also enhances their value in the eyes of the employers; sometimes they even are a good means to subdue rebellious male workers. Women moreover are more patient, they possess greater nimbleness and a more developed taste, qualities that make them better suited to many kinds of work than men" (BEBEL, 1910, p. 210).
} 
às exigências crescentes de sua força de trabalho sem oferecer resistência (BEBEL, 1910, p. 212, tradução nossa) ${ }^{2}$.

Conforme pudemos perceber, as desigualdades de gênero têm origem em uma macroestrutura de uma sociedade marcada pelas dissimetrias socioeconômicas. Assim, a luta de classes feminina é pertencente a um cenário maior de luta de classes, quer no âmbito nacional, quer no internacional. O trabalho feminino, por conseguinte, se engendra em uma lógica de mais-valia que visa a extrair com a exaustão da força de trabalho um máximo de lucratividade.

Em seu romance citado anteriormente, Patrícia Galvão (1994) constrói uma miscelânea de personagens femininas que trabalham, mormente, em fábricas de tecidos e ateliês, sob condições de pobreza, desigualdade e exploração. A obra se estrutura em forma de flashes e, "como um romance de tese, tem um objetivo claro: fotografar a relação capital versus trabalho, numa cidade industrial, como São Paulo" (SOARES, 1994, p. 134). Observemos o seguinte trecho do romance:

[...] Na grande penitenciária social os teares se elevam e marcham esgoelando.

— Malandros! É por isso que o trabalho não rende!

- Sua vagabunda! Bruna desperta. A moça abaixa a cabeça revoltada. É preciso calar a boca! Assim, em todos os setores proletários, todos os dias, todas as semanas, todos os anos! Nos salões dos ricos, os poetas lacaios declamam: - Como é lindo o teu tear! (GALVÃO, 1994, p. 19).

A primeira cena descrita se passa na Fábrica de Sedas Ítalo Brasileira. Bruna boceja em virtude da noite mal dormida e, ao se queixar de que os "ricos" podem descansar até mais tarde, quase se machuca nas máquinas. O companheiro chama a atenção da operária, mas o chefe da oficina se aproxima, os adverte acerca da "prosa" no local de trabalho, alcunha Bruna de "vagabunda" e ambos os trabalhadores de "malandros". A violência dirigida às classes subalternas, particularmente à operária, é notória ao longo do romance, podendo ser captada em tal trecho. O comentário seguinte contrapõe, de forma concisa e irônica, o exaustivo labor feminino na tecelagem ao lazer

\footnotetext{
2 "The endeavors of employers to lengthen the work day in order to extract larger profits from their workers is met with little resistance by women workers. That explains why in the textile industry, for instance, in which more than half of the workers are women the work day is longest. It was necessary therefore that government protection by limiting the hours of work should begin with this industry. Women being accustomed to an endless work day by their domestic activity, submit to the increased demands upon their labor power without offering resistance" (BEBEL, 1910, p. 212).
} 
do burguês salonista que, durante os ricos encontros, observa o "poeta lacaio" declamar elogios ao "tear" da amada.

Dentre o mosaico de personagens construído pela autora, encontramos duas figuras preponderantes na empreitada revolucionária: as operárias sindicalistas Rosinha Lituânia e Otávia, as quais corporificam um discurso que vai de encontro às "virtudes" das operárias, apontadas por Bebel (1910) - a pouca articulação e a submissão irrestrita às precárias e desiguais condições de trabalho. O trecho abaixo demonstra a articulação político-didática de Rosinha Lituânia, explicando a um rapaz sua condição de explorado: “[...] Um rapazinho se espanta. Ninguém nunca lhe dissera que era um explorado. Rosinha Lituânia explica: O dono da fábrica rouba de cada operário o maior pedaço do dia de trabalho. É assim que enriquece à nossa custa! [...]" (GALVÃO, 1994, p. 21).

Às mulheres que tinham instrução - financiada custosamente pela família pequeno-burguesa - havia o destino de serem professoras: "Escola Normal do Brás. Reduto pedagógico da pequena burguesia. $\mathrm{O}$ estudo não é muito caro. Os pais querem que as filhas sejam professoras, mesmo que isso custe comer feijão, banana e broa todo dia”. (GALVÃO, 1994, p. 38). Bebel (1910) analisa o trabalho feminino e aponta que as jovens, especialmente as mais adequadas aos padrões estéticos vigentes, eram empregadas como garçonetes, costureiras em ateliês e, quando conseguiam estudar, como professoras; mesmo assim, recebendo um salário menor do que o dos homens para desempenharem a mesma função.

No romance de Pagu (1994), como possibilidade de ascensão social, há a esperança de um matrimônio vantajoso, como no caso de Eleonora, desposada pelo rico Alfredo Rocha. Porém, à mulher negra e pobre como Corina, levada pela esperança de um amor romântico, resta concretizar o destino de corpo vulnerável e duplamente estigmatizado - por sua configuração étnica e por sua classe social. A personagem ignora a luta de classes e, depositando suas esperanças em se casar com um burguês, torna-se amante de Florino. A história de Corina, como a de milhares de proletárias pobres e negras, tem um desfecho trágico: abandonada e grávida, torna-se prostituta; o filho nasce com deformidades e morre; a jovem é presa em seguida e, após cumprir a pena, retorna à prostituição.

Assim, Corina não partilha da mesma "sorte" de Eleonora - casar-se com um rico burguês -, demonstrando que, não obstante o mito do amor romântico concorra na captura da classe operária, tal esperança é marcada pelo tom da pele branca, o que leva Corina a odiar e maldizer a própria cor: 
Por que nascera mulata? E tão bonita! Quando se pinta, então! O diabo é a cor! Porque essa diferença das outras! O filho era dele também. E se saísse assim, com a sua cor de rosa seca! Por que os pretos têm filhos? Xi! Se o Florino soubesse da gravidez!

Corina expulsa, chora na sarjeta, rodeada. Algumas mulheres falam com ela. Mas as crianças gritam, implacáveis de moral burguesa.

— Puta! — Olha a barriga dela! (GALVÃO, 1994, p. 51).

Denunciando um feminismo branco e burguês dentro do próprio movimento de contracultura, Parque Industrial (1994) retrata uma jocosa cena presenciada por Alfredo no bar de um luxuoso hotel. Trechos como o descrito abaixo permeiam toda a obra Parque Industrial (1994) e reforçam a luta de classes feminina como pertencente a um macrocosmo, ao binômio oprimido-opressor, em que as cidadãs - sufragistas burguesas, buscando os direitos apenas de sua classe, consideram as operárias como "analfabetas" e "excluídas por natureza":

[Alfredo] Acorda com o alvoroço de mulheres entrando. São as emancipadas, as intelectuais e as feministas que a burguesia de São Paulo produz. [...]

O barman cria cocktails ardidos. As ostras escorregam pelas gargantas bem tratadas das líderes que querem emancipar a mulher com pinga esquisita e moralidade.

Uma matrona de gravata e grandes miçangas aparece espalhando papéis.

- Leiam. O recenseamento está pronto. Temos um grande número de mulheres que trabalham. Os pais já deixam as filhas serem professoras. E trabalhar nas secretarias... Oh! Mas o Brasil e detestável no calor. Ah! MonPalais de Glace!

- Se a senhora tivesse vindo antes, podíamos visitara cientista sueca...

- Ah! Minha criada me atrasou. Com desculpas de gravidez. Tonturas.

Esfriou demais o meu banho. Também já está na rua! [...]

- O voto para as mulheres está conseguido! É um triunfo!

- E as operárias?

- Essas são analfabetas. Excluídas por natureza.

$\mathrm{O}$ garçom do grande hotel tem um sorriso significativo. Alfredo também. Paga. Sai. Toma o elevador para o 2oadar (GALVÃO, 1994, pp. $77^{-78)}$.

Além da importância da inserção da luta de classes feminina em um cenário nacional e internacional, como propõe Losurdo (2015), há no romance a crença no poder emancipatório da luta revolucionária quando confiada ao próprio proletariado. Alexandre é negro, pobre e, embora não saiba nem ler nem escrever, discursa "de um trabalhador para outro", arrebatando as multidões. A personagem, em diálogo com um companheiro, afirma que a esperança emancipatória não deve ser depositada em lugar algum senão na própria classe oprimida. 
— Então quem é que indireita? [a situação]

- Quem?

- Nós, os trabalhadores! Os explorados é que precisam fazer a revolução.

Um operário pequenino comenta.

- Não se faz a revolução porque a maioria do povo é que nem eu! Confesso que tenho medo da polícia. Quem quiser que faça... (GALVÃO, 1994, p. 100).

\section{Considerações finais}

Tendo como fio condutor a luta de classes feminina, este trabalho se propôs a comentar o panorama traçado em Parque Industrial (1994), de Patrícia Galvão, no que tange à dissimetria entre os membros das classes burguesa e operária durante o processo de industrialização da década de 1930, na cidade de São Paulo. A obra é composta por personagens-tipo que representam tanto os lugares sociais ocupados por jovens operárias, quanto às características que trazem consigo, instrumentos de subjugamento do outro à condição de absoluta miserabilidade social. Para tal, dialogamos com o conceito de regime estético de Rancière e com as considerações de Bebel (1910) e de Losurdo (2015) acerca da assunção por parte das operárias de determinadas ocupações no sistema capitalista.

O regime estético da arte é indissociável do conceito de democracia e representa a destituição das hierarquias entre os temas e as formas, o que permite tanto uma visibilização de elementos considerados anódinos, quanto uma redistribuição da partilha do sensível. Assim, política e estética formam uma coalizão e articulam associações entre o fazer estético e o comprometimento político e social. A obra Parque Industrial (1994) é construída por meio do entrelaçamento entre o político e o estético, endossando o poder revolucionário do proletariado. Na obra de Pagu, a revolução trata-se de uma interrupção ativa na marcha do progresso, ao invés de um resultado natural do curso da história. Assim, a obra critica qualquer sinal de comodismo e de passividade, uma vez que, como diria Benjamin (1994) nos anos 30, "o capitalismo não vai morrer de morte natural". 
Nossa análise não visa a esgotar as possibilidades interpretativas e consideramos, inclusive, que muitos pontos podem ser levantados acerca da obra: como, por exemplo, o intermezzo ocupado pelos policiais enquanto lumpenproletariado - lumpenproletariat -, aqueles que, a despeito de sua condição miserável, não tomam parte na luta de classes e apenas servem como massa de manobra para a burguesia.

\section{Referências}

BEBEL, August. Woman and Socialism. Socialist literature company: New York, 1910.

BENJAMIN, Walter. "O narrador". In: Magia e técnica, arte e política: ensaios

sobre literatura e história da cultura. Trad. Sérgio Paulo Rouanet. $7^{\underline{a}}$ ed. São Paulo: Brasiliense, 1994, pp. 222-232 (Obras escolhidas; v. 1).

GALVÃO, Patrícia. Parque industrial. São Paulo: Edufscar, 1994.

GRIMM, Jacob e Wilhelm. "Rumpelstiltzchen". In: Contos maravilhosos infantis domésticos. São Paulo: Cosac Naify, 2012, p. 260-261, Tomo I.

LOSURDO, Domenico. A luta de classes: uma história política e filosófica. Trad. Silvia de Bernardinis. Boitempo: Rio de Janeiro, 2015.

RANCIÈRE, Jacques. A partilha do sensível. Trad. Mônica Costa Netto. $2^{\underline{a}}$ ed. São Paulo: Ed 34, 2009. . "Literatura impensável". In: Políticas da escrita.

Trad. Mônica Costa Netto. São Paulo: Editora 34, 1995. p. 25-45.

SOARES, Luís Eustáquio. "Literatura, imperialismo mundial integrado e biopolítica: Parque Industrial, Marco Zero e PanAmérica". Estudos de literatura brasileira contemporânea, n. 52, p. 122-147, set./dez. 2017.

\footnotetext{
"Mestra em Letras pela Universidade Federal do Espírito Santo (Ufes-2016), Doutoranda em Letras pelo Programa de Pós graduação em Letras/PPGL-Ufes e Bolsista pela Fundação de Amparo à Pesquisa e Inovação do Espírito Santo (Fapes).
} 